\title{
REVISION OF FAILED TOTAL HIP ARTHROPLASTY
}

\author{
ROLF EJSTED, NIELS JENTOFF OLSEN
}

From Kolding Hospital, Kolding, Denmark

\begin{abstract}
Ninety-seven revisions of total hip replacements are reviewed with a median time of observation of 47 months. Satisfactory pain relief was obtained in $86 \%$. There were six complete failures which were reduced to three by further surgery. One hip became infected and was excised. In 12 cases the revisions were complicated by peroperative fractures and in five by dislocations. Radiographic analysis disclosed a high percentage of periarticular ossification and 25 cases of radiographic loosening of the femoral implant.
\end{abstract}

The clinical results of revision of failed total hip replacement have been uncertain and in infected cases some authors have recommended excision arthroplasty (Hunter et al. 1979). In cases of aseptic failure, varying degrees of success in revision have been reported (Dandy and Theodorou 1975; Broughton and Rushton 1982; Wallensten and Olsson 1982). We report our experience with revision of total hip arthroplasty at The Department of Orthopaedic Surgery, Kolding Hospital, in patients observed for at least two years.

\section{PATIENTS AND METHODS}

Between 1977 and 198297 total hip replacements were revised in 87 patients ( 43 men and 44 women); in nine patients replacements were revised bilaterally and in one patient the hip was revised twice. The median age at the time of revision was 71 years (range 33 to 87 years). The time between the primary arthroplasty and the last revision was 43 months (range 4 to 145 months); $75 \%$ of the patients had had symptoms for less than 24 months (mean 12 months).

The original diagnosis was osteoarthritis in 74 patients, rheumatoid arthritis in 2, aseptic necrosis in 7 and secondary arthritis in 4 patients. The exchanged prostheses were: 86 Ring prostheses, 5 McKee-Farrar, 2 Charnley, 3 Lubinus and 1 Stanmore prosthesis. The implant used at revision was in every case a Lubinus prosthesis. The indication for revision was in every case a painful hip in the presence of clinical and/or radiographically suspected loosening of the prosthesis.

Revision arthroplasty took place in an ordinary operating theatre. The exchange prosthesis was inserted

R. Ejsted, MD, Orthopaedic Registrar

N. J. Olsen, MD, Senior Orthopaedic Registrar

Department of Orthopaedic Surgery, Kolding Hospital, DK 6000

Kolding, Denmark.

Requests for reprints should be sent to Dr N. J. Olsen. (C) 1987 British Editorial Society of Bone and Joint Surgery 0301-620X/87/1027\$2.00 into gentamicin-impregnated polymethylmethacrylate and all patients received antibiotics before and after operation.

By the time of review six patients had died from causes unrelated to the hip and four patients could not be followed up because of severe mental or physical disease. These 10 patients, representing 12 revisions, were excluded from the evaluation. A further five revisions were excluded - four because of failure and one because of a recent femoral shaft fracture which made evaluation impossible. The exclusions are, however, all included in the discussion of complications and failures.

There were thus 80 revised replacements available for the clinical and radiographic evaluation. Their median time of observation was 47 months (range 25 to 84 months). The patients were evaluated according to the system of Merle d'Aubigné and Postel (1954) as modified by Charnley (1972), which is detailed in Table I. The radiographs obtained at follow-up examination were analysed for signs of loosening and position of implants (Gruen, McNiece and Amstutz 1979).

\section{RESULTS}

Operative findings. The suspected loosening was confirmed at operation in all cases. In 74 cases both the femoral and the acetabular implants were loose; in 17 the femoral implant alone was loose and in six cases the acetabular implant alone. In 83 of the arthroplasties the loosening was aseptic. In 13 cases a positive culture was obtained during operation. In one further case, which was known to be infected, the pus was sterile; this patient had been treated with antibiotics for several months before revision. The cultured organisms were Staphylococcus aureus in three cases and Staphylococcus albus in seven; there was one case each of infection with Pseudomonas, Proteus and Streptococcus.

Pain relief. The mean grading of pain before revision was 2.4 and at follow-up it was 5.5 , indicating that $86 \%$ of the hips were in Grades 5 and $6 ; 75 \%$ were completely free from pain. In $14 \%$ of the hips, the pain relief was 
Table I. System of evaluation proposed by Merle d'Aubigné and Postel (1954) and modified by Charnley (1972)

\begin{tabular}{|c|c|c|}
\hline Pain & Total movement & Walking \\
\hline 1. Severe and spontaneous & 1. 0 - 30 degrees & $\begin{array}{l}\text { 1. Few yards or bedridden } \\
\text { Two sticks or crutches }\end{array}$ \\
\hline $\begin{array}{l}\text { 2. Severe on attempting to walk } \\
\text { Prevents all activity }\end{array}$ & 60 degrees & 2. Time and distance very limited with or without sticks \\
\hline 3. Tolerable, permitting limited activity & 3. 100 degrees & $\begin{array}{l}\text { 3. Limited with one stick (less than one hour) } \\
\text { Difficult without a stick } \\
\text { Able to stand for long periods }\end{array}$ \\
\hline $\begin{array}{l}\text { 4. Only after some activity } \\
\text { Disappears quickly with rest }\end{array}$ & 4. 160 degrees & $\begin{array}{l}\text { 4. Long distances with one stick } \\
\text { Limited without a stick }\end{array}$ \\
\hline $\begin{array}{l}\text { 5. Slight or intermittent } \\
\text { Pain on starting to walk but getting less with normal activity }\end{array}$ & 5. 210 degrees & 5. No stick but a limp \\
\hline 6. No pain & 260 degrees & 6. Normal \\
\hline
\end{tabular}

Group $A$ : Only one hip involved. No other condition interferes with walking

Group $B$ : Both hips involved. No other condition interferes with walking

Group $C$ : Other conditions interfere with walking

unsatisfactory (Table II). One hip, assessed as Grade 1, had a loose femoral implant with a slip of $2 \mathrm{~mm}$ between implant and cement along the lateral border. The prosthesis had shifted from a valgus position into varus. In five cases the residual pain was ascribed to periarticular ossification. In the remaining five, there was no reasonable explanation of the pain: these were assessed as Grade 4 in four and Grade 2 in one.

Range of movement. The mean grade increased from Grade 4.1 before revision to Grade 4.9 at follow-up (Table III). Only one hip had a reduction in range and this one was greatly restricted by severe periarticular ossification.

Walking ability. The mean grading of Group A hips before revision was 2.3 and at follow-up 5.2. When Group B hips were included the mean pre-operative grading was 2.1 and at follow-up 5.0 (Table IV). In Group $\mathrm{C}$ the improvement in function was negligible. The mean grading changed from 1.7 to 2.4 (Table V). Assessment in relation to infection. When we compared the hips with aseptic loosening to those with positive cultures pre-operatively, there was no difference with regard to pain relief. The mean grading for aseptic loose hips changed from 2.5 to 5.5 and for septic loose hips from 2.1 to 5.5. The assessment of movement and walking ability also was exactly the same for the two groups.

\section{Radiographic analysis}

Acetabular component. In 42 arthroplasties there was an incomplete radiolucent zone at the bone/cement border measuring 1 to $3 \mathrm{~mm}$; in 34 arthroplasties this was in the lateral third of the acetabular roof. In 78 arthroplasties more than two-thirds of the acetabular implant was covered by bone; the remaining two were uncovered laterally.

Femoral component. In 25 of the femoral components there was a radiolucent zone at the bone/cement border
Table II. Grading of pain in 80 revision arthroplasties

\begin{tabular}{lrrrrrr}
\hline Grade & 1 & 2 & 3 & 4 & 5 & 6 \\
\hline Before revision & 14 & 33 & 27 & 4 & 2 & 0 \\
At follow-up & 1 & 3 & 3 & 4 & 9 & 60 \\
\hline
\end{tabular}

Table III. Range of movement in 80 revision arthroplasties

\begin{tabular}{lcccccc}
\hline Grade & 1 & 2 & 3 & 4 & 5 & 6 \\
\hline Before revision & 3 & 6 & 5 & 38 & 26 & 2 \\
At follow-up & 2 & 0 & 4 & 15 & 40 & 19 \\
\hline
\end{tabular}

Table IV. Assessment of walking for 61 Group A and B revision arthroplasties

\begin{tabular}{lrrrrrr}
\hline Grade & 1 & \multicolumn{1}{c}{ 2 } & \multicolumn{1}{c}{3} & 4 & 5 & 6 \\
\hline Before revision & 13 & 31 & 15 & 1 & 1 & 0 \\
At follow-up & 1 & 2 & 7 & 12 & 3 & 36 \\
\hline
\end{tabular}

Table V. Assessment of walking for 19 Group $C$ revision arthroplasties

\begin{tabular}{lllllll}
\hline Grade & 1 & 2 & 3 & 4 & 5 & 6 \\
\hline Before revision & 8 & 9 & 2 & 0 & 0 & 0 \\
At follow-up & 3 & 7 & 7 & 2 & 0 & 0 \\
\hline
\end{tabular}

more than $1 \mathrm{~mm}$ wide; in 12 this was limited to the proximal, lateral half of the interface, in four to the lateral and the medial, and in five to the medial part only; in only four was it around the distal half of the implant. Four arthroplasties showed a lucent zone measuring 2 to $5 \mathrm{~mm}$ between femoral component and cement at the proximal lateral border of the implant. In one case the radiolucent zone exceeded $5 \mathrm{~mm}$ in width. 
Calcar resorption and implant subsidence. In 64 arthroplasties there was no detectable resorption of the calcar; 14 arthroplasties showed resorption of 1 to $5 \mathrm{~mm}$, mostly as a cyst-like resorption, and in two the resorption measured more than $5 \mathrm{~mm}$. With the radiographs available we were not able to detect any subsidence.

Position of the implant. Forty-seven implants were placed in a neutral position, 15 in valgus and 18 in varus.

Periarticular ossification. Thirty-seven revision arthroplasties were complicated by periarticular ossification. In nine the ossification was so extensive that it occupied the whole space between prosthesis and pelvis, either medial or lateral to the hip. The mobility of the hips with milder degrees of ossification was not significantly decreased. In the majority of cases the ossification was without clinical significance, but in five cases the hips were painful.

\section{Failures and complications}

Out of 97 revision arthroplasties, six were classified as complete failures.

Case 1. A 76-year-old man who had a McKee-Farrar prosthesis exchanged because of aseptic loosening presented one year later with an Escherichia coli infection in the arthroplasty; he had a total excision.

Case 2. A 74-year-old woman who had a Ring prosthesis exchanged dislocated twice within the next two months. The acetabular cup was probably too vertical; a new cup was inserted more horizontally and there were no further dislocations.

Case 3. A 72-year-old woman had a Ring prosthesis exchanged because of aseptic loosening. Five years later the arthroplasty became painful and radiographs disclosed a loose femoral component. A second revision was undertaken, both components being exchanged and nine months postoperatively the result was excellent.

Case 4. A 70-year-old man who had a Ring prosthesis exchanged because of aseptic loosening dislocated three years later without any obvious reason. At operation for a second revision both the acetabular and the femoral component were found to be loose. The components were exchanged but the result was not satisfactory at follow-up two years later.

Case 5. An 86-year-old woman who had a Ring prosthesis exchanged dislocated three times within the first month because the neck of the prosthesis was too short. It was replaced with a prosthesis with a long neck and, at follow-up three years later, the result was excellent. This second revision was included in the evaluation.

Case 6. A 69-year-old woman had a Ring prosthesis exchanged, and because of persisting pain in the hip, a second revision was undertaken two years later. Loosening of the acetabular cup was suspected but could not be confirmed at operation; nevertheless a new cup was inserted. The result was disappointing. The probable explanation of the pain was degenerative changes in the lumbar spine.
In nine cases fractures of the greater trochanter or calcar complicated the revision arthroplasty; four of these fractures needed reduction and fixation with cerclage wires. In two cases the lateral femoral cortex was penetrated during reaming of the canal, and in one a spiral fracture of the femoral shaft beneath the tip of the stem occurred during reduction of the hip and was fixed with an AO plate. The remaining two were minor fractures and required no special treatment. All these intra-operative fractures healed without further complications and did not interfere with the final result.

In four cases dislocation of the revised replacement took place within five or six weeks of operation: two of these were reoperated (Cases 2 and 5) and the other two were successfully treated with closed reduction and immobilisation for three weeks. One replacement dislocated three years postoperatively (Case 4.)

\section{DISCUSSION}

The results of primary total hip arthroplasty have generally been satisfactory. The rate of excellent and good results has been in the order of $80 \%$ to $93 \%$ and with few complications (Charnley 1972; Beckenbaugh and Ilstrup 1978; Olsson, Jernberger and Tryggö 1981). The results of revision, however, have been doubtful. Dandy and Theodorou (1975), in a report on revision of the McKee-Farrar prosthesis, record 23\% which ended up with an excision arthroplasty; no less than $17 \%$ of their revisions became infected. Hunter et al. (1979) report on 140 revisions: only $24 \%$ obtained a satisfactory result, $32 \%$ of the revisions became infected and $22 \%$ ended up with a Girdlestone arthroplasty. Jones (1979) reviewed 82 revisions and found that $82 \%$ had a satisfactory result when the new prosthesis was inserted into cement. Wallensten and Olsson (1982) had 64\% satisfactory results among 40 revisons, of which $3.3 \%$ became infected. Broughton and Rushton (1982) report somewhat less satisfactory results. Carlsson, Josefsson and Lindberg (1978, 1980) and Buchholz et al. (1981) had satisfactory results with revision of infected total hip arthroplasty in about $90 \%$ of cases after one or more revisions. In our series $86 \%$ of the revisions obtained a satisfactory result with respect to pain relief. This is nearly as good as with primary arthroplasty.

The fact that the majority of our revisions were of uncemented Ring prostheses could be the reason for the high percentage of satisfactory results. Jones (1979) is of the opinion that such revisions are easier to perform; however, this is not our impression, for we had 12 intraoperative fractures and these occurred exclusively among the Ring revisions. This relatively high number is probably because the stem of the Ring prosthesis is fenestrated proximally and bone grows into the fenestrations, making the prosthesis difficult to remove. The majority of the fractures did not have any influence on the final result. 
The clinical results after revision of cemented prostheses were as good as those after uncemented prostheses, but our number of cemented prostheses was too small to allow any definite conclusions to be drawn.

Six per cent of revision arthroplasties required further surgery, and were therefore considered complete failures but this figure was reduced to $3 \%$ after a second revision. Only one revision became infected, corresponding to an infection rate of $1 \%$.

Radiographic analysis disclosed a relatively high number with periarticular ossification and a large percentage $(31.3 \%)$ of radiolucent zones around the femoral implant. Whether this radiolucency has any clinical significance remains to be seen (Olsson et al. 1981). We were not able to demonstrate any positive correlation between radiographic loosening and the clinical result. Neither could we demonstrate a positive correlation between implant position and radiographic loosening.

\section{REFERENCES}

Beckenbaugh RD, Ilstrup DM. Total hip arthroplasty: a review of three hundred and thirty-three cases with long follow-up. J Bone Joint Surg [Am] 1978;60-A :306-13.

Broughton NS, Rushton N. Revision hip arthroplasty: a retrospective study. Acta Orthop Scand 1982:53:923-8.
Buchholz HW, Elson RA, Engelbrecht E, Lodenkämper H, Röttger J Siegel A. Management of deep infection of total hip replacement. $J$ Bone Joint Surg [Br] $1981 ; 63-\mathrm{B}: 342-53$.

Carlsson ȦS, Josefsson G, Lindberg L. Revision with gentamicinimpregnated cement for deep infections in total hip arthroplasties. $J$ Bone Joint Surg [Am] 1978;60-A:1059-64.

Carlsson ȦS, Josefsson G, Lindberg L. Function of fifty-seven septic revised and healed total hip arthroplasties. Acta Orthop Scand $1980 ; 51: 937-41$.

Charnley J. The long-term results of low-friction arthroplasty of the hip performed as a primary intervention. $J$ Bone Joint Surg $[B r]$ $1972: 54-\mathrm{B}: 61-76$.

Dandy DJ, Theodorou BC. The management of local complications of total hip replacement by the McKee-Farrar technique. J Bone Joint Surg [Br] 1975;57-B:30-5.

Gruen TA, McNeice GM, Amstutz HC. "Modes of failure" of cemented stem-type femoral components: a radiographic analysis of loosening. Clin Orthop 1979;141;17-27.

Hunter GA, Welsh RP, Cameron HU, Bailey WH. The results of revision of total hip arthroplasty. J Bone Joint Surg [Br] 1979; 61-B:419-21.

Jones JM. Revisional total hip replacement for failed Ring arthroplasty. J Bone Joint Surg [Am] 1979;61-A:1029-34.

Merle d'Aubigné R, Postel M. Functional results of hip arthroplasty with acrylic prosthesis. J Bone Joint Surg [Am] 1954;36-A :451-75.

Olsson SS, Jernberger A, Tryggö D. Clinical and radiological long-term results after Charnley-Müller total hip replacement: a 5 to 10 year follow-up study with special reference to aseptic loosening. Acto Orthop Scand 1981:52:531-42.

Wallensten R, Olsson E. Rearthroplasty of the hip joint. Acta Orthop Scand 1982;53:273-7. 